\title{
Leadership \& Professional Development: Fighting Reputational Inertia
}

\author{
Kimberly D Manning, MD*, Jennifer O Spicer, MD, MPH²
}

${ }^{1}$ Department of Medicine, Emory University, Atlanta, Georgia; 'Division of Infectious Diseases, Department of Medicine, Emory University, Atlanta, Georgia.

"Becoming is better than being."

-Carol Dweck

he words spoken about her in the staff meeting were flattering. She'd just been acknowledged with a departmental teaching award for the second year in a row. With only 3 years under her belt since completing training, the former chief resident was living up to all they'd anticipated.

Eager students requested to be on her team and colleagues delighted in sharing patients with her. "Great, as always," her peers and learners said in hallways and evaluations. This would come to define her identity.

Things were going well. She was succeeding. But she began to wonder if this reciprocating engine of accolades represented who she truly was. Was she really that good? Was she an imposter? In her performance meetings, the feedback never wavered: "Great, as always."

The following year she would leave for a different job.

\section{THE THREAT OF REPUTATIONAL INERTIA}

While specific plans for growth and improvement often get laid out for struggling colleagues and learners, far less effort is devoted to coaching high performers. Feedback that consists of nonspecific compliments may hinder potential, growth, and job satisfaction. We outline strategies for preventing this professional plateau in those you lead.

\section{ENCOURAGE A GROWTH MINDSET}

In Mindset: The New Psychology of Success, psychologist Carol Dweck describes how emphasis on qualities such as "being smart" or, in this example, "great," underscores this "fixed mindset" that certain attributes are set in stone. ${ }^{1}$ Conversely, she defines the "growth mindset" as a belief that potential can be cultivated through efforts. Even when there aren't obvious issues with performance, the failure, fine-tuning, and feedback necessary for resilience and, ultimately, sustained growth require intention.

\section{Emphasize Effort}

Instead of lauding an individual for being "great, as always," consider focusing on the effort it required to get there. For example, regarding the aforementioned junior colleague who'd just won

*Corresponding Author: Kimberly D Manning, MD;

Email: kdmanni@emory.edu; Telephone: 404-778-1619.

Received: April 6, 2020; Accepted: April 7, 2020

C 2020 Society of Hospital Medicine DOI 10.12788/jhm.3438 awards, a typical compliment might be: "Wow, you're on fire!" An option, to promote a growth mindset, might be: "You work very hard at bedside teaching and innovative curriculum development. I'm happy to see that our learners and department have recognized your commitment and effort." This language also affirms others and makes achievements seem attainable to all.

\section{Provide Active Coaching}

Identifying specific opportunities for development can challenge individuals to expand their skills. Even those who are doing well have room to become even better. Coproduction of new milestones that push beyond current comfort zones can acknowledge current achievements while encouraging continued growth-and make things personal. For example, encouraging an individual to apply to a national faculty development program, such as the Society of Hospital Medicine's Academic Hospitalist Academy, could help them expand their skills and social network.

\section{Offer Meaningful Feedback}

Prioritizing feedback is essential for growth and peak performance. This can be particularly powerful when the observer moves beyond basic expectations to incorporate personal goals. Concrete feedback measured against individual potential then takes the place of nondescript compliments. For example, you could say: "Your teaching on systolic ejection murmurs was on target for the students. Next time I want to challenge you to broaden your teaching script to include points appropriate for more seasoned learners." This feedback leaves them with a set of tailored "marching orders" to guide practice and improvement.

\section{CONCLUSION}

No matter where a person stands on the spectrum of performance, growth in medicine relies on deliberate practice, active coaching, meaningful feedback, and graduated opportunities. Even the most proficient among us can stagnate without these things. If we aren't careful, this reputational inertia could amplify imposter syndrome, prevent individuals from achieving their full potential, and threaten faculty retention. Intentional work toward a growth mindset allows everyone to grow-and be seen.

Disclosures: The authors have nothing to disclose.

\section{Reference}

1. Dweck CS. Mindset: The New Psychology of Success. New York: Ballantine Books; 2008. 